\title{
Comparison Between Central Choroidal Thickness in Pregnant Diabetic Females and Pregnant Non-Diabetic Females
}

This article was published in the following Dove Press journal: Clinical Ophthalmology

\author{
Hisham Samy Shalaby (D) \\ Marwa Ebrahim EISebaay (D) \\ Mohamed Mahmoud Samy ${ }^{2}$ \\ 'Department of Ophthalmology, Faculty \\ of Medicine, Ain Shams University, Cairo, \\ Egypt; ${ }^{2}$ Department of Obstetrics and \\ Gynecology, Faculty of Medicine, Ain \\ Shams University, Cairo, Egypt
}

Objective: To compare choroidal thickness in pregnant women with and without diabetes mellitus (DM).

Methods: Sixty pregnant females (60 eyes) were enrolled in this cross-sectional controlled study. They were divided into two groups: Group A (30 patients; 30 eyes) were pregestational diabetic pregnant females, while Group B (30 patients; 30 eyes) were non-diabetic pregnant females. Exclusion criteria were high-risk pregnancy, diabetic retinopathy in Group A subjects, systemic or ophthalmological pathology, drug intake other than vitamin supplements and diabetic medications, and large errors of refraction. All patients underwent full ophthalmological examination and enhanced depth imaging optical coherence tomography (EDI-OCT) to measure the choroidal thickness in the nine zones of the Early Treatment Diabetic Retinopathy Study (ETDRS) map.

Results: Our results show that Group A eyes (of pregnant diabetic females) had a highly significant greater choroidal thickness than Group B eyes (of pregnant non-diabetic females) in all nine zones of the ETDRS map ( $p$-value $<0.01$ ). Moreover, we found a positive linear correlation between the duration of DM and the degree of choroidal thickening.

Conclusion: Pregnant diabetic females have a thicker choroid than that of pregnant nondiabetic females.

Keywords: choroidal thickness, diabetes, optical coherence tomography, pregnancy

\section{Introduction}

Pregnancy triggers vascular and metabolic changes in the eye. ${ }^{1}$ It may also aggravate pre-existing ocular disorders such as diabetic retinopathy. Other retinal diseases induced by pregnancy are eclampsia-associated retinopathy and central serous chorioretinopathy (CSC). ${ }^{2-4}$ The choroid is a highly vascular tissue, responsible for more than $70 \%$ of the blood flow in the eye. ${ }^{5}$ Hence, the choroid of a pregnant female is affected by haemodynamic and possibly hormonal factors. As a matter of fact, the choroidal thickness has been shown to significantly decrease in healthy pregnant women during the third trimester compared to the first trimester. ${ }^{6}$ Moreover, pregnancy when associated with pre-eclampsia has been shown to increase choroidal thickness. $^{7}$

Furthermore, placental release of anti-insulin hormones, including growth hormone, placental lactogen, and progesterone, is responsible for the development of gestational diabetes mellitus (GDM), which has an incidence ranging from $2 \%$ to $9 \%$. $^{8}$
Correspondence: Hisham Samy Shalaby Department of Ophthalmology, Faculty of Medicine, Ain Shams University, Abbassia Square, Cairo II59I, Egypt Tel +00201003641789

Email hisham_ophth@yahoo.com 
Optical coherence tomography (OCT), used to examine retinal disease, is capable of choroidal visualization due to enhanced depth imaging technology (EDI-OCT). Few studies have used the EDI-OCT to compare choroidal thickness in pregnant women to that of non-pregnant women. ${ }^{9-11}$ However, such earlier studies did not take into account the effect of endocrinal factors (such as diabetes) on choroidal thickness during pregnancy.

We aim through this study to compare the choroidal thickness in the macular area in diabetic pregnant females to that of non-diabetic pregnant females. We postulate that diabetes mellitus (DM) could aggravate the physiological changes in the choroidal thickness that happen during pregnancy.

\section{Subjects and Methods}

A cross-sectional controlled study was conducted in Ain Shams University Hospitals, Cairo, Egypt, after approval by the University Ethical Committee and in accordance with the 1964 Helsinki declaration and its later amendments. The study was conducted between September 2018 and February 2019. A written informed consent was taken from each participating subject, prior to recruitment. The study was divided into two subgroups: Group A consisted of 30 eyes of 30 pregnant women with pre-conception DM (12 type $1 \mathrm{DM}$ and 18 type $2 \mathrm{DM}$ ), while Group $\mathrm{B}$ involved 30 eyes of 30 non-diabetic pregnant females. Subjects were enrolled from routine pregnancy follow up visits at the Obstetrics and Gynecology Department, Ain Shams University Hospitals. We included pregnant females with gestational age 9 to 13 weeks. Exclusion criteria were any high-risk pregnancy (which was defined as high blood pressure, renal disease, thyroid disease, autoimmune diseases, smoking and history of using recreational drugs), diabetic retinopathy or macular edema in Group A subjects, any systemic or ophthalmological pathology (save for diabetes mellitus in Group A patients), intake of systemic drugs other than vitamin supplements and diabetic medications, and large errors of refraction (spherical equivalent $> \pm 2.0$ diopters).

The patients were subjected to complete ocular examination including best-corrected visual acuity, refraction, slit-lamp biomicroscopy, intraocular pressure measurement and dilated funduscopy (diabetic females with diabetic retinopathy or macular edema were excluded from the study at this point).

Choroidal thickness was measured using the EDI mode of the Spectral Domain-OCT (Retinascan RS-3000 Advance;
NIDEK, Gamagori, Japan). All scans were taken by a single experienced operator after pupillary mydriasis using tropicamide $0.5 \%$ eyedrops. The images were taken from $12 \mathrm{pm}$ to 2 $\mathrm{pm}$ to minimize circadian changes in choroidal thickness. ${ }^{12}$ All subjects were requested to refrain from drinking coffee 6 hours prior to image capture to avoid the effect of caffeine on choroidal thickness. ${ }^{13}$ The OCT scans were taken using 12 macular radial lines using image averaging from 120 images to obtain high definition scans. The camera was approximated to the eye till an inverted image was obtained to achieve the choroidal mode, and then the image was captured when it was sufficiently clear with high signal strength. All images were checked and those with artefacts were discarded. Subfoveal choroidal thickness (SFCT) was measured perpendicularly from the hyper-reflective outer border of the retinal pigment epithelium (RPE) to the posterior boundary of choroid at the sclero-choroidal interface (which was drawn using the embedded software). The Early Treatment Diabetic Retinopathy Study (ETDRS) grid was superimposed onto the choroidal map dividing the macula into 9 zones, bordered by rings of 1,3 and $6 \mathrm{~mm}$ diameter. The zones are: central subfoveal zone (CSF); superior inner macular zone (SIM), inferior inner macular zone (IIM), temporal inner macular zone (TIM), nasal inner macular zone (NIM); superior outer macular zone (SOM), inferior outer macular zone (IOM), temporal outer macular zone (TOM) and nasal outer macular zone (NOM).

Data were collected, coded, tabulated, and then analysed using Statistica ${ }^{\circledR}$ program. Numerical values between the two groups were compared using unpaired $t$-test. All data are expressed as the mean \pm standard deviation. Correlation was tested using Pearson Correlation Coefficient.

P-values $<0.05$ were considered significant, while $\mathrm{P}$-values $<0.01$ were considered highly significant.

\section{Results}

All demographic and clinical data for the two groups are shown in Table 1. There was no significant difference between the two groups as regards age, gestational age, best-corrected visual acuity, spherical equivalent or intraocular pressure.

Our results revealed that pregnant diabetic females in Group A had a thicker choroid at the subfoveal zone (356.4 $\mu \mathrm{m}, \mathrm{SD} \pm 28.1$ ) compared to pregnant nondiabetic females in Group B $(291.7 \mu \mathrm{m}, \mathrm{SD} \pm 67.5)$. This difference was highly significant (P-value $<0.0001$ ) and is shown in Table 2 and Figure 1. 
Table I Demographic and Clinical Data of the Study Population

\begin{tabular}{|l|l|l|l|}
\hline & Group A & Group B & P-value \\
\hline Mean age in years (range) \pm SD & $32.07(28-39) \pm 3.55$ & $31.20(23-38) \pm 5.66$ & 0.48 \\
Mean gestational age in weeks (range) \pm SD & $11.2(10-12) \pm 0.92$ & $11.8(9-13) \pm 1.49$ & 0.07 \\
Mean duration of diabetes mellitus in years (range) \pm SD & $12.27(6-17) \pm 4.24$ & - & - \\
Mean best corrected visual acuity in decimals (range) $\pm S D$ & $1.0(0.8$ to I.2) \pm 0.09 & $1.0(0.8$ to 1.2$) \pm 0.09$ \\
Mean spherical equivalent in diopters \pm SD & $-0.6 \pm 0.58$ & $-0.4 \pm 0.31$ & 1 \\
Mean intra-ocular pressure in mmHg \pm SD & $17.36 \pm 2.13$ & $16.64 \pm 2.5 \mathrm{I}$ & 0.1 \\
\hline
\end{tabular}

Abbreviation: SD, standard deviation.

Table 2 Mean Choroidal Thickness in 9 Zones of the Early Treatment Diabetic Retinopathy Study Map

\begin{tabular}{|l|l|l|l|}
\hline & Group A & Group B & P-value \\
\hline Subfoveal choroidal thickness (SFCT) & $356.4 \mu(\mathrm{SD} \pm 28 . \mathrm{I})$ & $291.7 \mu(\mathrm{SD} \pm 67.5)$ & $<0.000 \mathrm{I}$ \\
Superior inner macular zone (SIM) & $353.4 \mu(\mathrm{SD} \pm 38.0)$ & $31 \mathrm{I} .1 \mu(\mathrm{SD} \pm 37.7)$ & $<0.000 \mathrm{I}$ \\
Nasal inner macular zone (NIM) & $347.1 \mu(\mathrm{SD} \pm 32.77)$ & $292.4 \mu(\mathrm{SD} \pm 51.99)$ & $<0.000 \mathrm{I}$ \\
Inferior inner macular zone (IIM) & $353.8 \mu(\mathrm{SD} \pm 30.94)$ & $318.6 \mu(\mathrm{SD} \pm 48.0)$ & 0.0013 \\
Temporal inner macular zone (TIM) & $349.2 \mu(\mathrm{SD} \pm 34 . \mathrm{I})$ & $313.2 \mu(\mathrm{SD} \pm 38.4)$ & 0.0003 \\
Superior outer macular zone (SOM) & $352.6 \mu(\mathrm{SD} \pm 32.7)$ & $2704.8 \mu(\mathrm{SD} \pm 32.86)$ & $<0.000 \mathrm{I}$ \\
Nasal outer macular zone (NOM) & $328.3 \mu(\mathrm{SD} \pm 39.1)$ & $297.5 \mu(\mathrm{SD} \pm 35.54)$ & $<0.000 \mathrm{I}$ \\
Inferior outer macular zone (IOM) & $345.3 \mu(\mathrm{SD} \pm 24.32)$ & $286.0 \mu(\mathrm{SD} \pm 43.32)$ & $<0.000 \mathrm{I}$ \\
Temporal outer macular zone (TOM) & $340.36 \mu(\mathrm{SD} \pm 29.34)$ & $0.000 \mathrm{I}$ \\
\hline
\end{tabular}

Abbreviation: SD, standard deviation.

In addition, Group A patients have a greater mean choroidal thickness at $3 \mathrm{~mm}$ in all 4 zones, and this difference is highly significant (SIM zone $\mathrm{P}<0.0001$, NIM zone $\mathrm{P}<0.0001$, IIM zone $\mathrm{P}=0.0013$ and TIM zone $\mathrm{P}=0.0003$ ). This is shown in Table 2 and Figure 2. The IIM zone has the greatest mean choroidal thickness for both groups (353.8 $\mu \mathrm{m} \pm 30.94$ for Group A and 318.6 $\mu \mathrm{m} \pm 48.0$ for Group B), while the NIM zone has the least mean choroidal thickness in both groups $(347.1 \mu \mathrm{m} \pm 32.77$ for Group A and $292.4 \mu \mathrm{m} \pm 51.99$ for Group B).

Similarly, Group A patients have a greater mean choroidal thickness at $6 \mathrm{~mm}$ in all four zones, which is highly significant (SOM zone $\mathrm{P}<0.0001$, NOM zone $\mathrm{P}<0.0001$,

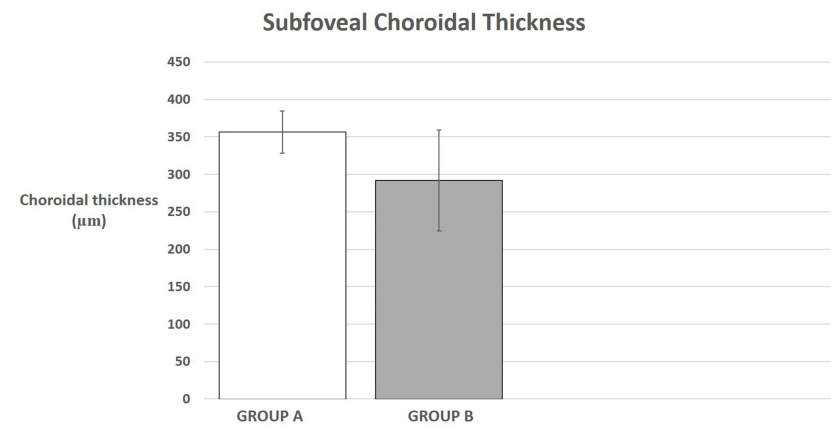

Figure I Central subfoveal choroidal thickness in Groups A and B.
IOM zone $\mathrm{P}<0.0001$ and TOM zone $\mathrm{P}<0.0001)$. This is shown in Table 2 and Figure 3. The SOM zone has the greatest mean choroidal thickness in both groups (352.6 $\mu \mathrm{m} \pm 32.7$ for Group A and $304.8 \mu \mathrm{m} \pm 32.86$ for Group B), while the NOM zone has the least mean choroidal thickness in both groups (328.3 $\mu \mathrm{m} \pm 39.1$ for Group A and $270.0 \mu \mathrm{m} \pm 49.84$ for Group B).

Table 3 shows the Pearson Correlation Coefficient for pregnant diabetic patients in Group A assessing the correlation between the duration of DM and choroidal thickness (where $r=1$ is total positive linear correlation, $r=0$ is no

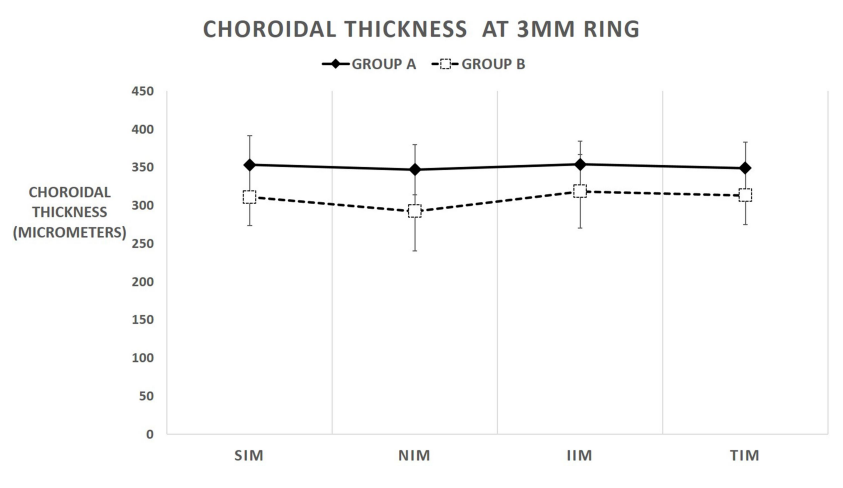

Figure 2 Choroidal thickness at central $3 \mathrm{~mm}$ ring. Superior inner macular zone (SIM), nasal inner macular zone (NIM), inferior inner macular zone (IIM) and temporal inner macular zone (TIM). 


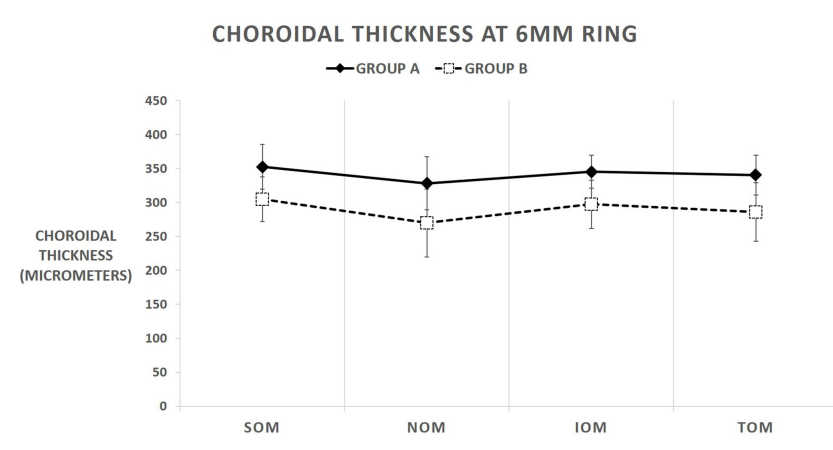

Figure 3 Choroidal thickness at central $6 \mathrm{~mm}$ ring. Superior outer macular zone (SOM), nasal outer macular zone (NOM), inferior outer macular zone (IOM) and temporal outer macular zone (TOM).

linear correlation and $\mathrm{r}=-1$ is total negative linear correlation). Our results indicate that there is a highly positive linear correlation between the duration of DM and the degree of choroidal thickening for all nine zones of the ETDRS map.

\section{Discussion}

The choroid is one of the most metabolically dynamic tissues in the body and is thus prone to influence from not only the hormonal changes of conception ${ }^{6,9}$ but also endocrinal disorders such as DM. ${ }^{14}$

Results of our study show that diabetic pregnant females have a greater choroidal thickness compared to their non-diabetic counterparts (Figure 4). This difference was noted in all ninezones of the ETDRS map. This is in contrast with the results of Acmaz et al, ${ }^{15}$ who found that the choroid was thicker in pregnant non-diabetic females (393.77 $\mu \mathrm{m} \pm 61.83$ ), compared to diabetic pregnant females (367.54 $\mu \mathrm{m} \pm$ 62.72). However, it should be noted that the difference in thickness they discovered was statistically non-significant, and that they only enrolled females with GDM in their work. Our study, on the other hand, included females who had pre-gestational DM. Moreover, Acmaz et al focused on central choroidal thickness only, while we studied the choroid in all nine zones of the ETDRS map. It is worth noting that Acmaz et al illustrated that choroidal thickness was significantly thicker in the pregnant females (with or without DM) than in the healthy non-pregnant females (322.49 $\mu \mathrm{m} \pm 65.58$, $\mathrm{p}$-value $<0.001)$. This may be attributed to increased ocular blood flow during pregnancy, $65 \%$ to $85 \%$ of which is directed to the choroid. ${ }^{16,17}$

Similarly, our results do not agree with the findings of Benfica et al. ${ }^{18}$ This cross-sectional study measured the choroidal thickness of non-diabetic pregnant women and pregnant women with gestational DM, type $2 \mathrm{DM}$ and type 1 DM. Compared to the non-diabetic controls, only pregnant women with type $1 \mathrm{DM}$ had a significantly thinner choroid on subfoveal and temporal locations, while subjects with type 2 and gestational DM showed no significant difference. Nevertheless, it should be noted that unlike our work, they included gestational DM. Additionally, they conducted their study on pregnant women in the third trimester, while our subjects were in their first and second trimesters.

The fact that choroidal thickness increases during pregnancy is ascertained by the work of Ulusoy et $\mathrm{al}^{19}$ That studied revealed that non-pregnant females had lower choroidal thickness $(320.86 \pm 59.18 \mu \mathrm{m})$ compared to pregnant females $(387.97 \pm 59.91 \mu \mathrm{m})$ and that difference was statistically significant (p-value $<0.001$ ).

Again, our data did not concur with the results of de Freytas et al. ${ }^{20}$ In that study, the choroidal thickness was compared between diabetic patients with macular edema and non-diabetics. It was revealed that the mean thickness

Table 3 Pearson Correlation Coefficient for Duration of DM and Choroidal Thickness

\begin{tabular}{|l|l|l|}
\hline & $\begin{array}{l}\text { Pearson Correlation Coefficient } \\
\boldsymbol{r} \text { for Duration of DM }\end{array}$ & $\begin{array}{l}\text { Pearson Correlation Coefficient P-value } \\
\text { for Duration of DM }\end{array}$ \\
\hline Central subfoveal zone (CSF) & 0.804 & $<0.000 \mathrm{I}$ \\
Superior inner macular zone (SIM) & 0.878 & $<0.000 \mathrm{I}$ \\
Nasal inner macular zone (NIM) & 0.885 & $<0.000 \mathrm{I}$ \\
Inferior inner macular zone (IIM) & 0.885 & $<0.000 \mathrm{I}$ \\
Temporal inner macular zone (TIM) & 0.868 & $<0.000 \mathrm{I}$ \\
Superior outer macular zone (SOM) & 0.863 & $<0.0001$ \\
Nasal outer macular zone (NOM) & 0.898 & $<0.0001$ \\
Inferior outer macular zone (IOM) & 0.872 & $<0.0001$ \\
Temporal outer macular zone (TOM) & 0.891 & $<0.0001$ \\
\hline
\end{tabular}



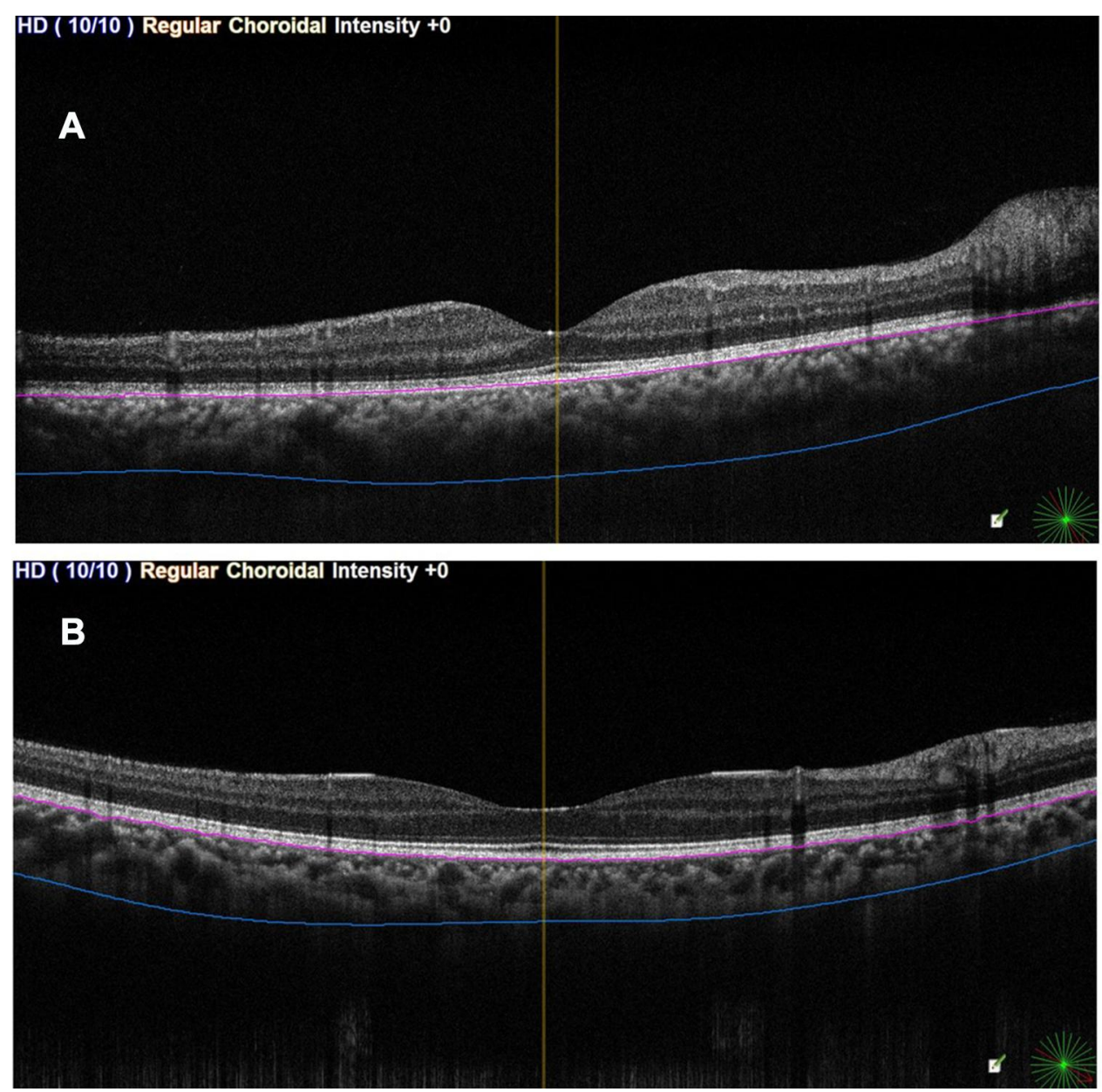

Figure 4 Enhanced depth imaging optical coherence tomography. Choroidal thickness is measured perpendicularly from outer limit of RPE to the posterior boundary of the choroid. (A) (above): Group A eye. (B) (below): Group B eye.

in diabetic patients $(192.82 \mu \mathrm{m}, \pm 83.51)$ was less than in non-diabetics $(222.90 \mu \mathrm{m}, \pm 85.85)$, and that difference was statistically significant $(\mathrm{p}=0.041)$. They attributed this difference to arteriolar narrowing, choriocapillary atrophy and disappearance of capillaries in eyes with diabetic retinopathy. Yet, it should be noted that this study unlike ours did not exclude patients who had received treatment for diabetic retinopathy such as retinal laser photocoagulation and intravitreal injection of anti-vascular endothelial growth factor (VEGF) agents. Choroidal thinning has been described after both treatments. ${ }^{21,22}$ Furthermore, that study did not include pregnant females at all and only focused on diabetics with macular edema, while our patients in Group A with DM were all without diabetic macular edema.

However, we found that our results agreed with the study of Rewbury et al, ${ }^{14}$ who concluded that there is a strong association between DM and choroidal thickness. Although their work did not include a control group of non- diabetic patients, they revealed that the choroidal thickness increases proportionally to the degree of diabetic retinopathy (mean $217.7 \mu \mathrm{m}$ in mild non-proliferative diabetic retinopathy, $221.7 \mu \mathrm{m}$ in moderate-severe non-proliferative diabetic retinopathy and $242.1 \mu \mathrm{m}$ in proliferative diabetic retinopathy). There was a statistically significant increase in choroidal thickness in proliferative diabetic retinopathy when compared with the mild non-proliferative diabetic retinopathy group $(\mathrm{P}$-value $=0.027)$. Diabetic macular edema was associated with a non-statistically significant increase in choroidal thickness $(225.4 \mathrm{m \mu})$ compared with eyes without diabetic macular edema $(209.3 \mu \mathrm{m})$, $\mathrm{P}$-value $=0.13$

Another study we found our results to be in accord with was that of Kim et al. ${ }^{23}$ In that study, choroidal thickness was less in eyes with no diabetic retinopathy $(262.3 \mu \mathrm{m} \mathrm{SD} \pm$ 68.4), compared to those with severe non-proliferative diabetic retinopathy $(291.1 \mu \mathrm{m} \mathrm{SD} \pm 107.7)$ and proliferative diabetic retinopathy $(363.5 \mu \mathrm{m} \mathrm{SD} \pm 74.9)$. Mean subfoveal 
choroidal thickness was significantly greater in eyes with proliferative diabetic retinopathy than in those with no diabetic retinopathy ( $\mathrm{P}$-value $<0.01)$, mild/moderate nonproliferative diabetic retinopathy ( $\mathrm{P}$-value $<0.01$ ), or severe non-proliferative diabetic retinopathy (P-value $<0.05)$. Although it does not include pregnant females, the study again suggests a close association between diabetes and choroidal thickness.

Savage et $\mathrm{al}^{24}$ used a computerized pneumotonometer to monitor choroidal blood flow in eyes with diabetic retinopathy. In comparison to non-diabetics, choroidal blood flow increased in patients with diabetic retinopathy. The analogy between the results of this hemodynamic study and our OCT results might indicate the increased release of VEGF causing vasodilation and increased choroidal blood flow, thus causing a thickening of the choroid.

It is also worth noting that the choroidal thickness in pregnant diabetics at $3 \mathrm{~mm}$ and $6 \mathrm{~mm}$ from the foveal center showed the least thickening at the nasal quadrants. Again, this is in concord with the work of Kim et al, ${ }^{23}$ who observed that choroidal thickening in eyes with diabetic retinopathy was least evident nasally. This may suggest that the architectural changes taking place in the choroid during pregnancy in diabetic patients may be zonally selective. Since the choroid is responsible for the blood supply of the outer five layers of the retina, this could have an influence on the evolution of diabetic retinopathy in such patients.

Our study has been limited by the number of patients enrolled. Moreover, further studies are required to assess choroidal morphology during different trimesters of pregnancy. Our study excluded any patients with diabetic retinopathy, so future studies could consider different grades of diabetic retinopathy as a factor influencing the structural changes in the choroid during pregnancy. Furthermore, future studies could focus on the choroidal vascularity index, which has been defined as the ratio of luminal area to total choroidal area. It has been used as a biomarker to evaluate the vascular status of the choroid. $^{25}$ Although choroidal thickness is a robust tool in clinical research, it reflects only the total choroidal vasculature with no distinctions between the two stromal and luminal vascular components. ${ }^{26}$ This could provide an explanation for the lack of consensus between different studies as to whether diabetes mellitus causes choroidal thinning or thickening. ${ }^{14,20}$

To conclude, the eyes of pregnant diabetic females had a greater choroidal thickness than that of non-pregnant diabetic females. This could be due to increased blood flow in the choroid, noted both in pregnancy and DM. The causes of the deterioration of diabetic retinopathy during pregnancy are still not fully understood. Diabetic choroidopathy might develop before the onset of retinopathy. ${ }^{27}$ Therefore, monitoring the choroidal architecture during pregnancy may prove to be a tool for identifying diabetic females who are at a greater risk for developing retinopathy.

\section{Funding}

The research was not funded.

\section{Disclosure}

The authors indicate no relationships/conditions/circumstances that present a potential financial conflict of interest. Costs were the responsibility of the authors and the instruments used in the study belong to the Faculty of Medicine, a part of Ain Shams University, which is a public governmental organization.

\section{References}

1. Kubica-Trzaska A, Karska-Basta I, Kobylarz J, Romanowska-Dixon B. Pregnancy and the eye. Klin Oczna. 2008;110(10-12):401-404.

2. Sunness JS. The pregnant woman's eye. Surv Ophthalmol. 1988;32:219-238. doi:10.1016/0039-6257(88)90172-5

3. Gouveia EB, Conceição PS, Morales MS. Ocular changes during pregnancy. Arq Bras Oftalmol. 2009;72:268-274. doi:10.1590/ S0004-27492009000200029

4. Errera MH, Kohly RP, da Cruz L. Pregnancy-associated retinal diseases and their management. Surv Ophthalmol. 2013;58:127-142. doi:10.1016/j.survophthal.2012.08.001

5. Mrejen S, Spaide RF. Optical coherence tomography: imaging of the choroid and beyond. Surv Ophthalmol. 2013;58(5):387-429. doi:10.1016/j.survophthal.2012.12.001

6. Dadaci Z, Alptekin H, Oncel Acir N, Borazan M. Changes in choroidal thickness during pregnancy detected by enhanced depth imaging optical coherence tomography. Br J Ophthalmol. 2015;99 (9):1255-1259. doi:10.1136/bjophthalmol-2014-306343

7. Kim JW, Park MH, Kim YJ, Kim YT. Comparison of subfoveal choroidal thickness in healthy pregnancy and pre-eclampsia. Eye (Lond). 2016;30(3):349-354. doi:10.1038/eye.2015.215

8. Correa PJ, Vargas JF, Sen S, Illanes SE. Prediction of gestational diabetes early in pregnancy: targeting the long-term complications. Gynecol Obstet Invest. 2014;77:145-149. doi:10.1159/000357616

9. Takahashi J, Kado M, Mizumoto K, Igarashi S, Kojo T. Choroidal thickness in pregnant women measured by enhanced depth imaging optical coherence tomography. Jpn J Ophthalmol. 2013;57 (5):435-439. doi:10.1007/s10384-013-0265-5

10. Kara N, Sayin N, Pirhan D, et al. Evaluation of subfoveal choroidal thickness in pregnant women using enhanced depth imaging optical coherence tomography. Curr Eye Res. 2014;39(6):642-647. doi:10.3109/02713683.2013.855236

11. Rothwell RT, Meira DM, Oliveira MA, Ribeiro MF, Fonseca SL. Evaluation of choroidal thickness and volume during the third trimester of pregnancy using enhanced depth imaging optical coherence tomography: a pilot study. J Clin Diagn Res. 2015;9(8):NC08-NC11. doi:10.7860/JCDR/2015/12888.6402 
12. Zengin MO, Karahan E, Yilmaz S, Cinar E, Tuncer I, Kucukerdonmez C. Association of choroidal thickness with eye growth: a cross-sectional study of individuals between 4 and 23 years. Eye (Lond). 2014;28(12):1482-1487. doi:10.1038/eye.2014.227

13. Zengin MO, Cinar E, Karahan E, Tuncer I, Kucukerdonmez C. The effect of caffeine on choroidal thickness in young healthy subjects. Cutan Ocul Toxicol. 2015;34(2):112-116. doi:10.3109/15569527.2014.912659

14. Rewbury R, Want A, Varughese R, Chong V. Subfoveal choroidal thickness in patients with diabetic retinopathy and diabetic macular oedema. Eye. 2016;30:1568-1572. doi:10.1038/eye.2016.187

15. Acmaz G, Atas M, Gulhan A, et al. Assessment of macular peripapillary nerve fiber layer and choroidal thickness changes in pregnan women with gestational diabetes mellitus, healthy pregnant women, and healthy non-pregnant women. Med Sci Monit. 2015;21:1759-1764. doi:10.12659/MSM.893221

16. Centofanti M, Miqliardi R, Bonini S, et al. Pulsatile ocular blood flow during pregnancy. Eur J Ophthalmol. 2002;12(4):276-280. doi:10.1177/112067210201200404

17. Chen HC, Newsom RS, Patel V, Cassar J, Mather H, Kohner EM. Retinal blood flow changes during pregnancy in women with diabetes. Invest Ophthalmol Vis Sci. 1994;35(8):3199-3208.

18. Benfica CZ, Zanella T, Farias LB, Oppermann MLR, Canani LH, Lavinsky D. Macular choroidal thickness in pregnant women with type 1, type 2 and gestational diabetes mellitus measured by spectral-domain optical coherence tomography. Clin Ophthalmol. 2018;12:1259-1265. doi:10.2147/OPTH.S166620

19. Ulusoy DM, Duru N, Ataş M, Altınkaynak H, Duru Z, Açmaz G. Measurement of choroidal thickness and macular thickness during and after pregnancy. Int $J$ Ophthalmol. 2015;8(2):321-325. doi:10.3980/j.issn.2222-3959.2015.02.19
20. de Freytas A, Gallego Pinazo R, Cisneros Lanuza A. Subfoveal choroidal thickness in eyes with diabetic macular oedema using swept source optical coherence tomography. Arch Soc Esp Oftalmol. 2016;91:228-231. doi:10.1016/j.oftal.2015.12.015

21. Cho GE, Cho HY, Kim YT. Change in subfoveal choroidal thickness after argon laser panretinal photocoagulation. Int $J$ Ophthalmol. 2013;6:505-509. doi:10.3980/j.issn.2222-3959.2013.04.18

22. Lains I, Figueira J, Santos AR. Choroidal thickness in diabetic retinopathy: the influence of antiangiogenic therapy. Retina. 2014;34:1199-1207. doi:10.1097/IAE.0000000000000053

23. Kim JT, Lee DH, Joe SG, Kim J-G, Yoon YH. Changes in choroidal thickness in relation to the severity of retinopathy and macular edema in type 2 diabetic patients. Invest Ophthalmol Vis Sci. 2013;54:3378-3384. doi:10.1167/iovs.12-11503

24. Savage HI, Hendrix JW, Peterson DC, et al. Differences in pulsatile ocular blood flow among three classifications of diabetic retinopathy. Invest Ophthalmol Vis Sci. 2004;45:4504-4509. doi:10.1167/iovs.04-0077

25. Agrawal R, Gupta P, Tan K-A, et al. Choroidal vascularity index as a measure of vascular status of the choroid: measurements in healthy eyes from a population-based study. Sci Rep. 2016;6:21090. doi:10.1038/srep21090

26. Sezer T, Altınışık M, Koytak İA, Özdemir MH. The choroid and optical coherence tomography. Turk Oftalmoloiji Derg. 2016;46:30-37. doi:10.4274/tjo.10693

27. Yazici A, Sogutlu Sari E, Koc R, et al. Alterations of choroidal thickness with diabetic neuropathy. Invest Ophthalmol Vis Sci. 2016;57(4):1518-1522. doi:10.1167/iovs.15-17966
Clinical Ophthalmology

\section{Publish your work in this journal}

Clinical Ophthalmology is an international, peer-reviewed journal covering all subspecialties within ophthalmology. Key topics include: Optometry; Visual science; Pharmacology and drug therapy in eye diseases; Basic Sciences; Primary and Secondary eye care; Patient Safety and Quality of Care Improvements. This journal is indexed on PubMed

\section{Dovepress}

Central and CAS, and is the official journal of The Society of Clinical Ophthalmology (SCO). The manuscript management system is completely online and includes a very quick and fair peer-review system, which is all easy to use. Visit http://www.dovepress.com/ testimonials.php to read real quotes from published authors. 